Duncan Pedersen 1

\title{
Reformulando a violência política e efeitos na saúde mental: esboçando uma agenda de pesquisa e ação para a América Latina e região do Caribe
}

\author{
Reframing political violence and mental health outcomes: \\ outlining a research and action agenda for \\ Latin America and the Caribbean region
}

\footnotetext{
${ }^{1}$ Douglas Hospital Research Centre, McGill University. Pavilion Perry Rm. E-2135, 6875 LaSalle Blvd. Verdun, H4H 1R3, Montreal, Quebec, Canadá. duncan.pedersen@staff. mcgill.ca
}

\begin{abstract}
In recent decades, the number of people exposed to traumatic events has significantly increased as various forms of violence, including war and political upheaval, engulf civilian populations worldwide. In spite of widespread armed conflict, guerrilla warfare and political violence in the Latin American and Caribbean region, insufficient attention had been paid in assessing the medium and long-term psychological impact and additional burden of disease, death, and disability caused by violence and wars amongst civilian populations. Following a review of the literature, a few central questions are raised: What is the short, medium and long-term health impact of extreme and sustained forms of violence in a given population? How political violence is linked to poor mental health outcomes at the individual and collective levels? Are trauma-related disorders, universal outcomes of extreme and sustained violence? These questions lead us to reframe the analysis of political violence and mental health outcomes, and reexamine the notions of trauma, after which a research and action agenda for the region is outlined. In the concluding sections, some basic principles that may prove useful when designing psychosocial interventions in post-conflict situations are reviewed.
\end{abstract}

Key words Political violence, War trauma, PTSD, Mental health, Latin America and the Caribbean
Resumo Em décadas recentes, o número de pessoas expostas a eventos traumáticos tem aumentado significativamente, bem como formas de violência como guerras e revoluções políticas, que subjugam populações civis em todo o mundo. Apesar da disseminação dos conflitos armados, guerrilhas e violência política na América Latina e Caribe, atenção insuficiente tem sido dada para avaliar o impacto psicológico a médio e longo prazo e o peso das doenças, mortes, e invalidez provocadas pela violência e guerra contra populações civis. Algumas perguntas centrais são levantadas, a partir de revisão da literatura: qual o impacto na saúde da população, a curto, médio e longo prazo, por vivenciar violências extremas e continuadas? Como a violência política se relaciona com pobre saúde mental individual e coletiva? As desordens relacionadas aos traumas são conseqüências universais da violência extrema e continuada? Essas perguntas nos levam a reformular a análise da violência política e de suas conseqüências sobre a saúde mental e a reexaminar as noções de trauma e a agenda da pesquisa e ação para a região. Ao fim, são apresentados alguns princípios básicos que podem ser úteis ao se projetar intervenções psicosociais.

Palavras-chave Violência política, Trauma da guerra, TEPT, Saúde mental, América Latina e Caribe 


\section{Introdução}

Diversamente do que se pensava a princípio, fica cada vez mais comprovada a existência de maior complexidade no inter-relacionamento entre a violência e a saúde da população.

Nas últimas décadas, o número de pessoas expostas a acontecimentos traumáticos aumentou de maneira significativa à medida que várias formas de violência, inclusive guerras e convulsões políticas, engolfam as populações civis no mundo inteiro; contribuindo, assim, para um ônus adicional persistente de doenças, mortes e casos de invalidez ${ }^{1-4}$.

O impacto da violência política (i.e., conflitos armados, operações de guerrilha, combates, encarceramentos, torturas, estupros e outras atrocidades de guerra) na saúde coletiva e no bem-estar das populações, seja dentro do país ou no exílio, vai muito além da perda da vida e da destruição da infra-estrutura física. A aceitação geral é de que a devastação no tecido social e cultural, o declínio econômico e o empobrecimento, o deslocamento das trajetórias de vida das pessoas, juntamente com a depreciação da identidade e dos sistemas de valores (vitais, de várias maneiras, para a sobrevivência), tudo possivelmente tem implicações significativas para a saúde e o bem-estar dos sobreviventes. No entanto, parece haver desacordo especificamente no tocante àquilo que impacta a saúde da população e, em particular, sua saúde mental, e ao grau de importância do impacto.

Alguns indícios parecem sugerir que as guerras não só agravam o risco de morte e invalidez, pela ruptura da ordem social, como, o que é mais importante, também levam ao aumento significativo de violência interpessoal (i.e., homicídios, agressões a mulheres e crianças), suicídio, acidentes e lesões por causas externas, consumo excessivo de álcool e substâncias químicas, bem como a taxas mais elevadas de doenças infecciosas (i.e., malária e tuberculose), câncer cervical e doenças sexualmente transmissíveis, como HIV/Aids ${ }^{5},{ }^{6}$. Estes problemas se compõem do deslocamento forçado de grandes segmentos da população, não só expostos à contínua violência política, como também a várias formas de agressão, como o estupro, exploração e abuso sexual, em geral nas condições impiedosas das zonas-abrigo ou dos campos de refugiados. Segundo a Unicef, em Ruanda, grande parte das adolescentes do sexo feminino que sobreviveram ao genocídio de 1994 foram subseqüentemente estupradas 7 .

De uma perspectiva mais restrita, a literatura que enfoca os efeitos diretos da violência política e das guerras na saúde, em geral, tenta estabelecer vinculação frontal entre a experiência original do trauma e a severidade e persistência - por vezes durante 50 anos - de determinados sintomas (i.e., ansiedade, depressão, consumo excessivo de álcool e drogas, e transtorno de estresse pós-traumático - TEPT), em alguns indivíduos.

Na verdade, os indícios acumulados mostram com clareza que, a longo prazo, uma fração variável das pessoas expostas a acontecimentos extremamente traumáticos apresenta sintomas psicológicos residuais e persistentes ${ }^{8}$. Com relação aos sintomas apresentados a curto prazo, no entanto, parece haver diferentes opiniões em relação aos efeitos da exposição à violência extrema. Há uma persistente controvérsia entre especialistas, profissionais de saúde e terapeutas envolvidos nas intervenções pós-conflito/desastre sobre a importância e a aplicabilidade multi-setorial de construtos psiquiátricos convencionais do trauma, em particular o TEPT. Conquanto alguns especialistas internacionais argumentem que a reação a acontecimentos traumáticos envolve padrões reconhecíveis universalmente (inclusive condições médicas diagnosticáveis, tais como transtorno de estresse agudo e TEPT, capazes de serem amenizados por tratamentos-padrão), a crítica de outros sugere que os acontecimentos traumáticos têm significados e efeitos muito mais amplos, variados e complexos do que os reconhecidos pela nosologia ou pela prática psiquiátrica convencional9, 10. Esses efeitos, por sua vez, evocam um vasto leque de estratégias específicas de adaptação cultural, cujo entendimento é precário.

Summerfield ${ }^{11}$ lembra ser preciso maior cautela para evitar atribuições falsas quando se ignora a presença de variáveis confundíveis na cadeia de eventos que levam à doença mental ou aos estados emocionais acompanhados de nítidas e dolorosas lembranças do passado. Em termos fenomenológi$\cos$, no confronto da perda e da violência extrema, as reações emocionais resultantes não são necessariamente psicopatológicas; pelo contrário, ilustram aspectos de funcionamento cognitivo regular e ficam dentro da gama de reações psicológicas "normais" à adversidade.

Embora várias formas de intervenção de saúde mental possam ter um papel a desempenhar na recuperação do pós-conflito ou pós-desastre (se bem que a base de sua comprovação esteja longe de ser satisfatória), a medicalização dos programas de intervenção psicossocial, em termos de transtorno de estresse pós-traumático e construtos correlatos, em geral leva à aplicação imprópria 
de listas de verificação de sintomas, seguida da oferta dos serviços de terapia de traumas. Essa abordagem reflete, em parte, nosso entendimento limitado a respeito do relacionamento de uma série de possíveis efeitos na saúde, após a exposição a acontecimentos catastróficos e traumáticos. Além disto, em termos clínicos, sabemos pouco sobre quem deve (ou não) receber tratamento, e ainda menos acerca da razão de o tratamento funcionar em alguns casos, enquanto em outros, os resultados serem precários ou simplesmente ineficazes.

Para concluir esta etapa, gostaria de fazer uma breve introdução sobre as questões de resiliência, coesão social e capital social, como pertinentes à discussão da administração do trauma e da recuperação pós-conflito. Há literatura crescente sobre a resiliência diante da adversidade, com possíveis implicações significativas para o plano e a aplicação das intervenções. Nas últimas três décadas, alguns construtos correlatos, tais como "autoeficácia"12, "hardiness"13 (resistência), "resiliência"14, "capital social"15, "sentido de coerência"16, "recuperação"17 e, mais recentemente, "crescimento póstrauma"18, "coesão social" e "capital social"19, 20, aparecem com proeminência na literatura de psicologia social, sociologia médica e saúde pública. Estes construtos objetivam identificar recursos endógenos, individuais e coletivos, e atributos com propriedades protetoras, restauradoras e curativas, ou mesmo efeitos positivos, para vítimas e sobreviventes expostos a acontecimentos adversos e experiências traumáticas. Mais uma vez, a literatura parece indicar conclusões divergentes. Enquanto alguns buscam enfatizar a importância da resiliência e da coesão social na determinação dos efeitos da violência na saúde, outros parecem reduzir sua importância ou simplesmente ignorar a influência destes fatores na saúde mental.

\section{Síntese regional: América Latina e Caribe}

Apesar de difundido conflito armado, das operações de guerrilha e da violência política na região, não se dá atenção suficiente à avaliação do impacto psicológico geral e do ônus adicional de doenças, mortes e casos de invalidez causados por violência e guerras na população civil da América Latina e do Caribe ${ }^{21}$.

Está além do propósito deste trabalho examinar a vasta literatura sobre violência política e suas conseqüências no povo dessa região. Muitas das publicações tratam das conseqüências mais diretas da "guerra sucia" e da experiência traumática das famílias de desaparecidos e vítimas de tortura e/ou sobreviventes das atrocidades cometidas por ditaduras militares, como no caso da Argentina e do Chile, nas décadas de 1970 e $1980^{22-24}$. A Colômbia e o Haiti, dois países devastados por contínua e prolongada violência, agitação civil e problemas estruturais, têm sido citados na literatura, mas poucos autores focalizaram os efeitos na saúde e, menos ainda, as conseqüências da violência a longo prazo. Em países como Guatemala, Nicarágua e El Salvador, há um número crescente de relatórios oficiais e publicações científicas que tratam do impacto psicológico da violência política e das guerras na população local e em refugiados ${ }^{25-31}$.

Na América Latina, as lutas políticas contemporâneas emergentes, as guerras de baixa intensidade e a violência interpessoal afetaram de maneira desproporcional a população indígena. Há muitos exemplos recentes de conflitos que resultaram em grande número de mortes nas nações ameríndias: as execuções extrajudiciais dos índios misquitos, na Nicarágua; o extermínio em massa dos maias, na Guatemala, e dos tzotziles, em Chiapas, no México; o assassinato dos índios ianomâmis, na fronteira do Brasil com a Venezuela; e a aniquilação e o desaparecimento dos lavradores quíchuas, no planalto peruano. No Peru, consoante o relatório final apresentado pela Comisión de la Verdad y Reconciliación, as duas décadas de conflito armado (1980-2000) entre o Sendero Luminoso e os militares deixariam em seu rastro um total estimado de 69.280 mortos e desaparecidos, mais de 600 mil deslocados internamente e perdas materiais e econômicas indeterminadas. Detalhe ainda mais importante: a comissão concluiu que três quartos das vítimas eram falantes nativos quíchuas, o que reflete a "discriminação profundamente arraigada contra a população rural andina e sua marginalização impregnadas na sociedade peruana" 32 .

No caso da Guatemala, grandes segmentos da população foram deslocados devido à violência $\mathrm{e}$ ao conflito interno, a maioria deles índios maias das regiões Norte e Sudoeste do país. Estima-se que, nas últimas três décadas, aproximadamente 75 mil povos indígenas guatemaltecos desapareceram ou foram eliminados pela violência e mais de 350 mil fugiram para o exterior como refugiados, metade dos quais ainda se encontram no México e em outros países da região ${ }^{33}$. Conforme a Suprema Corte de Justiça da Guatemala, mais de 200 mil crianças perderam um dos pais ou ambos, por causa da violência indiscriminada e da repressão difundida.

Além disso, a vida dos povos indígenas na região Andina e na América Central torna-se cada vez mais ameaçada à medida que eles tentam defender suas 
terras e posses da contínua incursão de grupos insurgentes, forças especiais e militares. As lutas internas pelo poder geradas pela chegada de colonos migrantes (rancheiros), empresas madeireiras e mineradoras, traficantes de drogas, missionários e seitas religiosas, inclusive funcionários do governo encarregados do desenvolvimento de mega-projetos, em geral mantidos por órgãos internacionais de financiamento, também representam ameaças aos indígenas da região. Hoje, a saúde da população urbana e rural pobre da região é claramente um reflexo da poderosa influência concomitante do passado colonial, uma história de violência estrutural e aculturação forçada, e do implacável processo de mudança global. No contexto da globalização e da adaptação estrutural, o surgimento e a consolidação de políticas neoliberais e economias de livre mercado, ao invés de reduzir as desigualdades, aumentaram o fosso entre ricos e pobres, resultando em efeitos de precariedade na saúde. Além disso, a presença ameaçadora de múltiplos estressores, inclusive violência de várias fontes, cria novos riscos à saúde e, ao mesmo tempo, induz a profundas mudanças e transformações no modo de vida da coletividade. É contra esse pano de fundo de pobreza e impotência, desigualdades sociais e violência em suas várias formas, que as condições da saúde e, em particular, da saúde mental das populações indígenas locais, devem ser compreendidas.

É dentro desse contexto regional que precisamos reformular a análise da violência política e dos efeitos na saúde mental e, acima de tudo, reexaminar as noções de trauma de guerra e de seqüelas da violência política. Nas partes remanescentes deste trabalho, esboçamos uma agenda de pesquisa para a região da América Latina e do Caribe, com a atenção focada nas seguintes questões:

a) A necessidade de examinar os efeitos da violência política e das guerras não só em termos de acontecimentos estressantes imediatos e dificuldades econômicas e políticas, que são seus inevitáveis precursores, mas também de fazer as vinculações entre eles e as estruturas sociais e econômicas mais abrangentes em que se originam;

b) Em segundo lugar, ao tentar avaliar os efeitos na saúde e os traumas psicológicos como seqüelas da exposição à violência, devemos abordar o assunto não apenas do ponto de vista biomédico e clínico, como também da perspectiva social e epidemiológica. Isso exigiria o uso de métodos qualitativos (i.e., etnográficos) na documentação de idiomas locais da aflição e de amplo leque de reações ao trauma - inclusive reações adaptativas e estratégicas - em termos individuais e coletivos; c) A necessidade de explorar caminhos alternativos para curar e enfrentar as conseqüências da violência e buscar planejamento de intervenções inovadoras, inclusive avaliar intervenções médicas ou psicológicas em curso, que talvez ajudem ou impeçam a recuperação de experiências traumáticas.

\section{Reexame dos traumas de guerra e dos transtornos a eles relacionados}

Ao examinar a literatura sobre traumas, parece haver consenso de que foi John Erichsen, um médico britânico, o primeiro a se referir à noção de trauma como lesão mental, em sua obra On Railway and other injuries of the nervous system, publicada em $1866^{34}$. Erichsen deu a entender que, em acidentes ferroviários, lesões invisíveis e choques nervosos eram produzidos por abalos ou concussões na corda espinhal, algo que denominou de "espinha ferroviária". Os sintomas descritos foram palidez, tremores, crises de choro, inclusive estado de "perturbação natural da mente", após o acidente ferroviário, em geral seguidos por insônia, ansiedade, pulso fraco, etc. A lesão do sistema nervoso foi explicada por meio de uma analogia entre o choque nervoso e os efeitos de um imã submetido a forte golpe de martelo. Meio século depois, as noções de lesão traumática e choque nervoso continuaram a evoluir mediante os trabalhos de cientistas como Jean-Martin Charcot, Pierre Janet, W.H.R. Rivers e Ivan Pavlov.

Próximo à virada do século 20 e nos anos que se seguiram à Primeira Guerra Mundial, Sigmund Freud voltou sua atenção para o trauma como origem dos ataques histéricos e para o que mais tarde recebeu a denominação de "neuroses traumáticas de guerra". Afastando-se das explanações neurológicas, Freud considerou os sintomas da histeria como se resultantes de reminiscências ou lembranças de experiência traumática, também chamada "memória traumática". Esses foram os precursores do que posteriormente se descreveu como "epidemia de neuroses de guerra", caracterizada por dormência localizada, hipersensibilidade e dor, insensibilidade, contrações e paralisias musculares, sintomas gastrintestinais e cardiovasculares, entre outros, experimentados por reservistas do exército britânico. Essa coleção de sintomas polimórficos mais tarde foi rotulada de "traumatismo de guerra" pelo corpo médico do Real Exército e atribuída à exposição a explosivos nas linhas de frente ${ }^{35}$. Curiosamente, a explicação para "traumatismo de guerra" foi de muitas maneiras similar àquela dada para "espinha ferroviária": a exposição a ondas de 
choque produzidas pela proximidade de uma explosão causava concussões e transtornos vasculares, resultando em lesões e danos microscópicos nas estruturas histológicas do cérebro e do cordão espinhal.

Durante a Segunda Guerra Mundial, grande número de soldados norte-americanos exposto a combate desenvolveu ampla variedade de sintomas psiquiátricos, em geral classificados sob a rubrica geral de "neuroses de guerra". Muitos desses casos foram descritos como síndromes clínicas e rotulados de "ansiedade", "estados de conversão", "regressões somáticas" ou "transtornos psicossomáticos" e tratados como tais por um vasto conjunto de terapias: terapia abreativa, sono induzido por drogas, choques convulsivos, psicoterapia e terapia ocupacional.

Conforme proposta de Kirmayer ${ }^{36}$, o trauma pode ser visto de imediato como acontecimento sociopolítico, processo psicofisiológico, experiência física e emocional, em geral seguido de uma explicação e um tema narrativo. Visto dessa perspectiva, pode-se argumentar que o trauma de guerra não pode ser expresso apenas em termos políticos, cabendo também ser verificado em níveis múltiplos de experiência: mudanças fisiológicas (e.g. aumento na produção de catecolamina e cortisol), presença de lesões físicas e invalidez, parada no desenvolvimento (por exemplo, devido à desnutrição), efeitos psicológicos diversos e uma ampla gama de entidades comórbidas e doenças associadas a trauma (e.g. uso excessivo de substâncias químicas, tuberculose, Aids, etc.).

Da perspectiva biomédica, a neurobiologia do trauma oferece indícios de que o TEPT é biologicamente diferente de outras reações de estresse traumático (ou não traumático). Um estudo recente sobre a neurobiologia do TEPT ${ }^{37}$ aponta três importantes conjuntos de descobertas da pesquisa: alterações do eixo noradrenérgico, alterações neuroendócrinas, envolvendo o eixo hipotálamohipofisário-adrenal (HPA), e alterações neuroanatômicas, envolvendo o hipocampo. Além das mudanças noradrenérgicas, a exposição à violência extrema e ao estresse agudo provoca alterações neuroendócrinas moduladas pelo eixo HPA: a liberação do hormônio propulsor de corticotropina estimula o hormônio adernocortitrópico, que, por sua vez, estimula a secreção de cortisol (principal hormônio do estresse). O cortisol ativa uma cascata de reações fisiológicas relacionadas ao estresse. No estresse crônico (não traumático) os padrões do eixo HPA parecem se comportar de maneira diversa (como demonstrado pelos níveis inferiores de cortisol urinário em pacientes veteranos internados com TEPT). Em animais expostos a estressores de afastamento brusco, os pesquisadores descobriram células danificadas na região hipocampal do cérebro (também medida pelo volume hipocampal) similares ao dano induzido por glucocorticóides diretamente implantados no hipocampo. Esse indício preliminar das alterações nos volumes hipocampais (medidos por ressonância magnética em veteranos de combate e controles saudáveis) sugere que as modificações no tamanho e na função do hipocampo (e das amídalas) podem constituir um traço importante do TEPT crônico ${ }^{38}$.

As pesquisas em curso sobre trauma são realizadas não só por neurocientistas, mas também por clínicos e psicólogos, bem como por cientistas políticos, antropólogos e historiadores. Entretanto, a maioria dos estudos publicados enfoca um possível efeito principal da exposição à violência: o Transtorno de Estresse Pós-Traumático (TEPT). A categoria do diagnóstico de TEPT foi lançada em 1980, pela Associação Americana de Psiquiatria, na terceira edição do Manual de Diagnóstico e Estatística das Perturbações Mentais (DSM-III). Pressupõe-se que o conjunto essencial de perturbações e sintomas associados ao TEPT seja causado por experiências estressantes "fora do âmbito das experiências humanas usuais" e relacionadas à Guerra do Vietnã, tais como as experimentadas por ex-combatentes e pacientes da Administração de Veteranos dos Estados Unidos. O construto de diagnóstico de TEPT caracteriza-se por três aspectos principais: a) Recorrência de lembranças da experiência traumática (memórias visuais e sensoriais intensas e recordações intrusivas do acontecimento, acompanhadas de extrema aflição); b) Evitação de lembranças do trauma - inclusive insensibilidade, distanciamento e retraimento emocional - associada à incapacidade de vivenciar alegria e prazer; c) Padrão de excitação elevada (hipervigilância, irritabilidade, transtornos do sono e reação de sobressalto exagerada). Nas formas crônicas de TEPT, o padrão de hiperexcitabilidade e evitação talvez sejam as características clínicas dominantes ${ }^{39}$.

Desde o início da década de 1980, o trauma surge como conceito-chave heurístico em muitas das pesquisas sobre saúde mental, abrangendo os efeitos do desenvolvimento do trauma inicial em transtornos da personalidade a psicoses. No entanto, alguns autores começaram a desafiar com seriedade os modelos psicológicos ou psiquiátricos que postulam a existência de mecanismos biológicos, psicológicos e sociais baseados em pressuposições da universalidade do TEPT. A exposição ao trauma e o TEPT têm sido associados a pior saúde física, mas os papéis relativos à exposição ao 
trauma com o TEPT e o contexto geral ainda são contestados ${ }^{40}$.

De uma perspectiva clínica, o construto do diagnóstico de TEPT - primordialmente baseado na experiência de veteranos de guerra e de vítimas de outros tipos de trauma (estupro, agressões criminosas, tortura, acidentes e desastres naturais) - propiciou avanços na compreensão da doença manifestada em indivíduos que sofreram traumas de um único incidente (e.g. acidente de veículo). Essas pessoas, porém, apresentam em geral uma variedade de queixas e problemas psicológicos (e.g. somatização, depressão, amnésia e dissociação, etc.), entre as quais somente algumas recaem na definição estrita de TEPT.

Nas últimas décadas, a linguagem da violência, do terror e do deslocamento tem-se combinado com freqüência com o discurso do trauma e do estresse. Nas tradições popular e profissional do Ocidente, o "trauma" tornou-se uma categoria dominante para explicar por vezes as origens ou as causas de outros problemas, por vezes as conseqüências da exposição à violência provocada por conflito e guerra. É no Ocidente, onde o "trauma" passou a ser uma categoria emblemática, que ele se faz onipresente e invasivo em nosso cotidiano. Seu uso atingiu proporções epidêmicas: a mídia, o público, os esportes e as artes, os cientistas e os leigos, todos clamam a universalidade do "trauma" como efeito inevitável da exposição à violência.

Esse fenômeno de rápida expansão está amplamente disseminado e não só popularizou a noção de trauma na população em geral como também transformou seu significado e levou ao que tem sido denominado de "metamorfose do trauma". Segundo Young, essa transformação da noção do trauma ocorreu nas últimas décadas (e foi reforçada e acelerada depois "do 11 de Setembro"): de um problema limitado a veteranos de guerra e discutido por especialistas a uma questão comum debatida no dia-a-dia; de uma questão de certa forma restrita às vítimas diretamente afetadas por acontecimentos "além do alcance da experiência humana ordinária" a um fenômeno de proporções epidêmicas aplicado ao cotidiano, como acidentes de tráfego, partos difíceis, assaltos ou conhecimento pelo noticiário acerca da morte de alguém importante ${ }^{41}$.

As equipes psiquiátricas ou os terapeutas do trauma são imediatamente mobilizados após acidentes de trem ou de avião, desastres naturais ou causados pelo homem, ou outros incidentes, como tiroteios ou assaltos a banco. Nas nações ocidentais, o crescimento dos serviços de terapia em cada ângulo da vida escapou do questionamento crítico, em grande parte devido às dificuldades de se discernir onde termina um estado emocional desagradável e começa uma síndrome clínica ou um estado anormal. A expansão e a definição abrangente do trauma tornaram problemática a avaliação objetiva de sua existência; daí ser preciso cautela ao tentar determiná-la.

\section{Questões emergentes: delineamento de uma agenda de pesquisa regional}

A partir de um breve exame da literatura, começam a surgir algumas questões centrais pertinentes para a região da América Latina: Quais os impactos a curto, médio e longo prazo das formas extremas e contínuas de violência nas populações locais? Como a violência política está ligada a efeitos de saúde mental precária em termos individuais e coletivos? O TEPT e outros transtornos relacionados ao trauma são efeitos universais da violência capazes de serem aplicados como tais às populações da América Latina e do Caribe? Quais os fatores de risco que predizem os que serão mais afetados pela exposição à violência extrema? Qual o papel de outros males sociais, tais como racismo e exclusão social, juntamente com a pobreza e as guerras, na determinação da equação saúde e doença? Qual a produção social do sofrimento coletivo e individual? Qual o papel de outras forças em jogo, tais como a resiliência, a capacidade de enfrentamento e a densidade e qualidade das redes de apoio social? Quais as intervenções mais efetivas na promoção da resiliência e no fortalecimento da coesão social em determinada população afetada por conflito e violência?

Quaisquer que sejam os fatores estruturais, sociais e culturais a montante das causas e determinantes da saúde, em algum ponto - a jusantehá processos psicológicos e biológicos em curso, ligando a trajetória entre os determinantes do contexto macro (a economia política) aos mundos micro da experiência individual.

Quais são, então, as trilhas biopsicosociais, caso haja, entre o conflito étnico, a violência política, as guerras e os efeitos na saúde mental? Como essa teia de causas, ligações e cursos determina o nível de sofrimento, doença e morte em certa população? Por meio de que mecanismos as forças sociais, da pobreza ao racismo e à violência política, incorporam-se como experiência individual?

A maioria dessas perguntas ainda não tem uma resposta definitiva. Na verdade, como vimos acima, os cientistas se preocupam com essas questões desde o fim do século 19, quando o significado de 
"trauma" ampliou-se além da lesão física, passando a incluir males psicogênicos. Contudo, foi nessas últimas décadas que a pesquisa sobre o trauma surgiu como campo relevante de questionamento e assumiu caráter mais onipresente e compreensivo. Ao tentar explicar a ocorrência de doença, aflição e sofrimento social em relação à violência, é impossível ignorar as questões contextuais da pobreza e das desigualdades sociais.

Cientistas sociais críticos acreditam que a falta de explicitação do contexto (fontes sociais, políticas e econômicas da desigualdade) contribui para a leitura inadequada das realidades em que o sofrimento e a doença são produzidos. A omissão das origens sociais da dor e do sofrimento, em geral, resulta em alegações imodestas de causalidade, aumenta a tendência para a medicalização dos problemas sociais e, por fim, leva à ampliação das desigualdades sociais.

$\mathrm{Na}$ avaliação das condições relacionadas ao trauma e reação às mesmas, é de crucial importância não só enfocar as narrativas do trauma e o significado da experiência da enfermidade, como também entender e atuar no contexto, isto é, nos determinantes sociais e políticos da saúde e do sofrimento humano, permanecendo consciente dos riscos e interesses particulares de determinada perspectiva $\mathrm{e}$ da diversidade cultural da cura e das reações individuais e coletivas de enfrentamento.

Como vimos na seção anterior, o modelo médico do trauma, contudo, tem limitações importantes na captação das maneiras complexas como os indivíduos, as comunidades e os grandes grupos vivenciam forte trauma, socializam sua dor e reconstituem uma existência significativa. Sugeriuse que, nas populações latino-americanas, as seqüelas do trauma são vivenciadas como um feixe de sinais e sintomas que transcendem os limites restritos do TEPT e manifestados nos idiomas locais de dor e transtornos somatoformes diversos ${ }^{42}$.

Do ponto de vista epidemiológico, a magnitude e a distribuição dos transtornos relacionados ao trauma como experiência coletiva em populações locais da região exposta à violência política e a guerras contemporâneas estão longe de serem entendidas. Há algumas descobertas fortuitas, estruturas de análise não desenvolvidas e total falta de hipóteses sobre as questões básicas de como as pessoas vivenciam e são afetadas por violência política, conflito étnico e guerras. Os resultados preliminares de um estudo de campo recente no planalto peruano, que inclui uma pesquisa multisetorial realizada na população geral de uma área de alta exposição a acontecimentos traumáticos mais de uma década de extrema violência, ter- rorismo e atrocidades de guerra -, mostram uma grande proporção da população adulta (mais de $50 \%$ ) com resultado positivo quanto aos sintomas de esgotamento mental e cerca de um em cada quatro adultos (habitantes com mais de 14 anos de idade) entrevistados como sintomáticos de transtornos relacionados a trauma (e.g. TEPT). Claramente, as mulheres, principalmente viúvas e idosas, eram as mais afetadas, não só pelos efeitos a longo prazo da exposição a acontecimentos traumáticos, mas também, indiretamente, pela ruptura de suas redes sociais, baixa coesão social e isolamento relativo de seus pares, falta de alimento e abrigo e outras condições geralmente relacionadas ao colapso geral da economia local e às condições extremamente adversas impostas pelos guerrilheiros do Sendero Luminoso e pelas forças militares repressivas que operam na região ${ }^{42}$.

Sabemos que a maioria dos conflitos contemporâneos e operações bélicas modernas afetam as populações civis muitas vezes mais do que as forças armadas diretamente envolvidas nos confrontos - nas operações bélicas modernas, as taxas de mortalidade dos militares caíram consideravelmente. Sabemos também que, pelo menos na região da América Latina, grande parte desses conflitos armados envolve pessoas politicamente marginais e etnicamente distintas - as chamadas pessoas do "quarto-mundo"21. O terror de massa tornou-se uma estratégia deliberada, seguida tanto por exércitos insurgentes quanto repressivos: a destruição de lares, escolas, prédios religiosos, estradas e pontes, animais e plantações, bem como a tortura, o estupro e o encarceramento são banais. As operações bélicas modernas visam não só a aniquilar a vida, como também a destruir as "formas de vida", tentando eliminar grupos étnicos inteiros e erradicar culturas e sistemas sociais como um todo, minando, portanto, os meios críticos pelos quais as pessoas suportam e se recuperam do sofrimento e da perda ${ }^{10}$.

Finalmente sabemos, a partir das pesquisas epidemiológicas anteriores, realizadas com sobreviventes do holocausto nazista, que somente uma fração das pessoas expostas a acontecimentos traumáticos de longo prazo desenvolve sintomatologia compatível com o TEPT ${ }^{43}$. Isso foi confirmado por nosso estudo multisetorial supramencionado, realizado no planalto peruano, onde somente um em cada quatro adultos entrevistados $(\mathrm{N}=373)$ que foram expostos à extrema violência na década de 1980 relatou sintomas compatíveis com o diagnóstico de TEPT.

Hoje, não há intervenção humanitária ou programa de reabilitação que possa desconsiderar a re- 
construção do tecido social como preocupação primordial. Ainda assim, em cada vila ou comunidade em pequena escala, há influências endógenas, protetoras ou melhorativas, amplamente decorrentes de estruturas resilientes, bem como estratégias de sobrevivência e resolução de conflitos, seguidas pelas comunidades no pós-conflito. Incluem-se, entre outras: estratégias baseadas na comunidade para reconciliação, mudanças ideológicas (por exemplo, conversão para outras religiões ou conversões políticas), formas espontâneas de melhorar o apoio social (e.g. festivais comunitários, cerimônias religiosas e públicas, reuniões sociais em torno de acontecimentos importantes, etc.), grupos de auto-apoio (i.e., organizações comunitárias de viúvas e mulheres) e também sistemas de crença que oferecem a base para a criação de significado do trauma vivido. Preservar e fortalecer essas formas culturais de apoio para curar e enfrentar o problema devem constituir a prioridade das intervenções psicossociais ${ }^{44}$.

Conquanto no futuro próximo os medicamentos psicotrópicos, a terapia e as técnicas psicoterapêuticas possam se tornar parte importante do armamento das intervenções clínicas objetivadas, não devemos ignorar a importância dos recursos nativos para enfrentar e curar, nem a proporção significativa de pessoas que se recupera espontaneamente da exposição à violência extrema.

Apesar das várias formas de terapia individual disponíveis - quer comprovadamente eficientes, quer não -, devemos admitir que a medicalização dos programas de reabilitação restritos à aplicação imprópria de listas de verificação e oferta de "terapia do trauma" reflete uma compreensão limitada do relacionamento entre determinantes sociais criticamente importantes do sofrimento e o leque de possíveis efeitos na saúde, após exposição a acontecimentos traumáticos. Além disso, sabemos muito pouco a respeito de quem deve receber terapia individual, e menos ainda sobre a maneira e a razão de esta funcionar bem em alguns casos, e não em outros ${ }^{8}$. Mais ainda, é preciso admitir que temos conhecimento limitado de como construir, reparar e reforçar os vínculos sociais e as redes de apoio, fomentar a resiliência e aumentar a coesão social ou o capital social em sociedades devastadas por angústia, forte trauma e deslocamento.

Por fim, a maior parte das iniciativas de intervenção do trauma constitui empreendimento dispendioso importado para cenários de guerra pelo mundo afora: Margem Ocidental, Bósnia, Ruanda, África do Sul, América Central, Peru, Nepal,
Bangladesh, etc. As intervenções humanitárias são, afinal de contas, produto ideológico de uma cultura globalizante, apresentado como conhecimento decisivo e panacéia para todo o mundo não ocidental. Temos de reconhecer que esses cenários mundiais apresentam normas, valores e tradições diferentes, um leque de atribuições e entendimentos, formas diversas de expressar emoções, aflição e sofrimento e maneiras distintas de, diante de acontecimentos traumáticos, pedir ajuda, enfrentá-los e curá-los.

\section{Implicações dos programas de assistência humanitária e de reabilitação psicossocial}

Como corolário do que foi discutido acima, parece tempestivo examinar alguns princípios básicos ou etapas a serem seguidas, que podem ser úteis no planejamento de intervenções psicossociais em situações pós-conflito na América Latina e na região do Caribe. Em sua maioria, elas se baseiam em observações similares feitas por Ager ${ }^{44}$ em populações afetadas pela guerra, submetidas a testes de campo, e confirmadas por nossa própria experiência no desenvolvimento de um programa de estabilização pós-conflito e reabilitação psicossocial no planalto peruano ${ }^{45}$.

Em primeiro lugar, todas as iniciativas de intervenção em qualquer local dado devem ser planejadas de modo a envolver ruptura mínima das influências protetoras endógenas. Isto é, onde as estruturas comunitárias resilientes e as redes sociais sobreviveram ao conflito, os programas de assistência devem explicitamente procurar preservar esses recursos endógenos para enfrentar e curar, em vez de tentar substituí-los por ajuda externa.

Em segundo lugar, onde as influências protetoras foram desativadas ou são percebidas como claramente insuficientes para minorar a aflição e o trauma vividos, a intervenção deve objetivar o restabelecimento de mecanismos de proteção e oferta de apoio externo compensatório, como iniciativas de desenvolvimento comunitário, atividades geradoras de renda (oferta de pequeno crédito ou assistência financeira) ou programa de educação para a paz.

Somente quando as etapas supramencionadas já foram estabelecidas, e após cautelosa avaliação das necessidades existentes ainda não satisfeitas, é possível implementar uma terceira medida na forma de um pacote de intervenções terapêuticas objetivadas, dirigidas a indivíduos, famílias e grupos específicos com necessidade de atenção ou 
cuidado específico. Na dependência dos recursos disponíveis, pode-se realizar busca passiva ou por meio de testes dos casos de trauma, por intermédio de enfermeiras treinadas, na clientela carente de serviços médicos. Alternativamente, é possível delegar a busca dos casos às estruturas comunitárias existentes (i.e., associações sediadas na comunidade), a professores treinados ou a informantes-chave. As intervenções terapêuticas também devem levar em conta os recursos nativos disponíveis e a experiência comunitária sobre o que é capaz ou não de funcionar como solução efetiva. Em outras palavras, essa fase deve ser claramente participativa; e os serviços a serem prestados, derivados de um produto negociado com a comunidade como um todo e com os grupos vulneráveis (i.e., idosas ou viúvas), em vez de representar a decisão unilateral de um órgão externo ou profissional.

O caminho preferivel para estabelecer intervenções terapêuticas objetivadas deve ser o uso de uma abordagem hermenêutica, trazendo à tona, em primeiro lugar, os acontecimentos traumáticos conforme descritos pela população local e, em segundo lugar, os idiomas locais da aflição e seu significado, a fim de decodificar a construção cultural feita pelo paciente de sua própria enfermidade, enriquecendo e ampliando, assim, o leque de intervenções e administração clínica dos casos individuais.

No planejamento das reações humanitárias e estratégias para curar e enfrentar a violência e a adversidade, precisamos substituir o enfoque atual nos mecanismos intrapsíquicos e psicológicos por uma abordagem mais abrangente, visando ao contexto social e à vida comunitária, em que as pessoas se recuperam das experiências traumáticas. Conforme proposta de Bracken \& Petty, repensar o trauma da violência extrema e da guerra signifi- ca afastar-se da rotulação de indivíduos ou grupos como vítimas de estupro ou tortura. Envolve a preocupação de ajudar a reconstruir, ou inventar de outro modo, as estruturas sociais, por meio das quais as vidas são vividas e têm significado. A normalização e a recuperação, a partir dessa perspectiva, tocam todos os aspectos da sobrevivência social e econômica, abrangendo o contexto em que o desenvolvimento e a aprendizagem ocorrem e, para todos, envolvem as noções de justiça social, solidariedade, reconciliação e ruptura dos círculos de violência e impunidade ${ }^{10}$.

As experiências permanentes na estabilização e reabilitação psicológica pós-conflito na região da América Latina sugerem que as metas de paz, reconciliação e recuperação econômica não podem ser asseguradas por intervenções unilaterais ad hoc objetivando exclusivamente as vítimas de trauma e suas famílias. Os problemas subjacentes exigem participação de vários setores (agrícola, financeiro, de crédito, saúde, educação e justiça), que podem, por sua vez, envolver o estabelecimento de um diálogo aberto, não só com órgãos internacionais, doadores e instituições financeiras, como também com autoridades nacionais, regionais e locais.

Para finalizar, essas abordagens a reações humanitárias na região da América Latina vão exigir - tanto a curto quanto a longo prazo -, em primeiro lugar, um banco de dados mais robusto e provas empíricas resultantes de pesquisa; em segundo lugar, muito mais informações fornecidas pelas ciências sociais, tanto em programas de pesquisa, quanto de ação; e, em terceiro lugar, o sentido de justiça social e, acima de tudo, de "credibilidade" por parte das comunidades internacionais de doadores, agentes de governos e cientistas, além da atualmente existente. 


\section{Referências}

1. Pedersen D. Political violence, ethnic conflict, and contemporary wars: broad implications for health and social well-being. Soc Sci Med 2002; 55(2):175-90.

2. Ghobarah HA, Huth P, Russett B. The post-war public health effects of civil conflict. Soc Sci Med 2003; 59(4):869-84

3. Gustafson P, Gomes VF, Vieira CS, Jensen H, Seng R, Norberg $\mathrm{R}$, et al. Tuberculosis mortality during a civil war in GuineaBissau. JAMA 2001; 286(5):599-603.

4. Roberts L, Hale C, Belyakdoumi F, Cobey L, Ondeko R, Despines M, et al. Mortality in Eastern Democratic Republic of Congo. New York: International Rescue Committee; 2001.

5. Parker R. The Global HIV/Aids pandemic, structural inequalities, and the politics of international health. Am J Public Health 2002; 92(3):343-6.

6. Elbe S. Strategic implications of HIV/Aids. Adelphi Papers 2003; 357(1).

7. Unicef. The state of the world's children. Oxford: Oxford University Press; 1996.

8. Yehuda R, Hyman SE. The impact of terrorism on brain, and behavior: what we know and what we need to know. Neuropsychopharmacology 2005; 30:1773-80.

9. Young A. The Harmony of illusions: inventing post-traumatic stress disorder. New Jersey: Princeton University Press; 1995.

10. Bracken PJ, Petty C. Rethinking the trauma of war. Save the children. London: Free Association Books; 1998.

11. Summerfield D. War and mental health: A Brief Overview. BMJ $2000 ; 321: 232-5$

12. Bandura A. Self-efficacy: Toward a unifying theory of behavioral change. Psychol Rev 1977; 84:191-215.

13. Kobasa S. Stressful life events, personality, and health: An enquiry into hardiness. J Pers Soc Psychol 1979; 37:1-11.

14. Rutter M, Avshalom C, Moffitt TE. Using sex differences in psychopathology to study causal mechanisms: unifying issues and research strategies. J Child Psychol Psychiatry 2003; 44:1092-115.

15. Bourdieu P. The forms of capital. In: Richardson JG, editor. Handbook of theory and research for the sociology of education. New York: Greenwood; 1986. p. 241-58.

16. Antonovsky A. Unraveling the mystery of health: How people manage stress and stay well. San Francisco: Jossey-Bass; 1987.

17. Harvey M. An ecological view of psychological trauma and recovery. J Trauma Stress 1996; 9:3-23.

18. Tedeschi RG. Violence transformed: posttraumatic growth in survivors and their societies. Aggression and Violent Behaviour 1999; 4(3):319-41.

19. Coleman JS. Foundations of social theory. Cambridge: Harvard University Press; 1990.

20. Putnam RD. Bowling alone: The collapse and revival of american community. New York : Simon and Schuster; 2000.

21. Pedersen D. El impacto de la pobreza, el racismo y la violencia política sobre la salud mental de los pueblos indo-americanos. In: Bronfman M, Castro, R, organizadores. Salud, cambio social y política: Perspectivas desde América Latina. México: Edamex; 1999. p. 163-84.

22. Suárez-Orozco M. A Grammar of terror: Psychocultural responses to state terrorism in dirty war and post-dirty war Argentina. In: Nordstrom C, editor. The Paths to domination, resistance \& terror. Berkeley: Univ. of California Press; 1992. p. 219-59.

23. Lira E. Psicología de la amenaza política y del miedo. Santiago de Chile: Editorial Chileamérica; 1991.

24. Amnesty International. Annual review 2001. London: A.I. Publications; 2001.

25. Americas Watch and Physicians for Human Rights. Guatemala: Getting away with murder. New York: Americas Watch and Somerville; Boston: Physicians for Human Rights; 1991.

26. Dickson-Gomez J. Growing up in guerrilla groups: The longterm impact of being a child soldier in El Salvador's civil war. Ethos 2002; 30(4):325-56.

27. Garfield RM. War-related changes in health and health services in Nicaragua. Soc Sci Med 1989; 28(7):669-76.
28. Lundgreen RI, Lang R. There is no sea, only fish: Effects of United States policy on the health of the displaced in El Salvador. Soc Sci Med 1989; 27(7):697-706.

29. Martin-Baro I. Political violence and war as causes of psychosocial trauma in El Salvador. Int J Ment Health 1989; 18(1):3-20.

30. Martin-Baro I, Aron A, Corne S. Latin American Psychology and Social Commitment. Contemporary Psychology 1996; 41(5):468-9.

31. Summerfield D, Toser L. Low intensity war and mental trauma in Nicaragua: A study in a rural community. Med War 1991; 7(2):84-99.

32. Comisión de la Verdad y Reconciliación (CVR). Informe Final. Lima: CVR; 2003.

33. Oficina de Derechos Humanos, Arzobispado de Guatemala (ODHAG). Guatemala: Nunca más. Informe del Proyecto Interdiocesano de Recuperación de la Memoria Histórica. Guatemala: REMHI; 1998.

34. Erichsen JE. On Railway and Other Injuries of the Nervous System. In: Young A, editor. The Harmony of illusions: inventing post-traumatic stress disorder. New Jersey: Princeton University Press; 1995. p. 13-9.

35. Young A. Making Traumatic Memory. In: Young A, editor. The Harmony of illusions: Inventing post-traumatic stress disorder. New Jersey: Princeton University Press; 1995. p. 13-42.

36. Kirmayer LJ. Confusion of the senses: Implications of ethnocultural variations in somatoform and dissociative disorders for PTSD. In: Marsella AJ, Friedman MJ, Gerrity ET, Scurfield RM, editors. Ethnocultural aspects of posttraumatic stress disorder: Issues, research and clinical applications. Washington D.C.: American Psychological Assoc.; 1996. p. 131-63.

37. Vedantham K, Brunet A, Neylan TC, Weiss DS, Marmar CR. Neurobiological findings in posttraumatic stress disorder: A review. Dialogues Clin Neurosci 2000; 2(1):23-9.

38. Nemeroff CB, Bremner JD, Foa EB, Mayberg HS, North CS, Stein MB. Posttraumatic stress disorder: a state-of-the-science review. J Psychiatr Res 2006; 40(1):1-21.

39. Van der Kolk B. Posttraumatic stress disorder and the nature of trauma. Dialogues Clin Neurosci 2000; 2(1):7-22.

40. Gorst-Unsworth C, Goldenberg E. Psychological sequelae of torture and organized violence suffered by refugees from Iraq. Trauma-related factors compared with social factors in exile. $\mathrm{Br}$ J Psychiatry 1998; 172:90-4.

41. Young A. A Description of how ideology shapes knowledge of a mental disorder (Posttraumatic Stress Disorder). In: Lindenbaum S, Lock M, editors. Knowledge, power, and practice. Berkeley: University of California Press; 1998. p. 108-28.

42. Pedersen D, Gamarra J, Planas ME, Errázuriz C. Violencia política y salud mental en las comunidades altoandinas de Ayacucho, Perú. In: Cáceres C, Cueto M, Ramos M, Vallenas V, organizadores. La salud como derecho ciudadano: Perspectivas y propuestas desde América Latina. Lima: Universidad Peruana Cayetano Heredia; 2003. p. 289-307.

43. Breslau N. Epidemiology of trauma and posttraumatic stress disorder. In: Yehuda R, editor. Psychological trauma. Washington D.C.: American Psychiatric Press, Inc.; 1998. p. 1-30.

44. Ager A. Tensions in the psychosocial discourse: Implications for the planning of interventions with war-affected populations. Dev Pract 1997; 7(4):402-7.

45. Pedersen D. Pathways for healing and coping with violence, terror and dislocation. In: Rehabilitation and Research Centre for Torture Victims (Copenhagen) and Oficina de Derechos Humanos, Arzobispado de Guatemala (Guatemala) (RCT/ODHAG), editors. Mental health and community intervention (Special Report). Antigua, Ciudad de Guatemala; 2002. p. 93-102.

Artigo apresentado em 3/09/2006

Aprovado em 23/03/2006

Versão final apresentada em 23/03/2006 